Article

\title{
Vitamin D Insufficiency and Bone Mineral Status in a Population of Newcomer Children in Canada
}

\author{
Hassanali Vatanparast ${ }^{1,2, *}$, Christine Nisbet $^{3}$ and Brian Gushulak ${ }^{4}$ \\ 1 Division of Nutrition and Dietetics, College of Pharmacy and Nutrition, University of \\ Saskatchewan, Saskatoon, SK S7N 5A2, Canada \\ 2 School of Public Health, University of Saskatchewan, Saskatoon, SK S7N 5A2, Canada \\ 3 Division of Nutrition and Dietetics, College of Pharmacy and Nutrition, University of Saskatchewan, \\ Saskatoon, SK S7N 5A2, Canada; E-Mail: christine.nisbet@usask.ca \\ 4 Migration Health Consultants, Qualicum Beach, British Columbia, V9K 1S9, Canada; \\ E-Mail: brian.gushulak@gmail.com \\ * Author to whom correspondence should be addressed; E-Mail: vatan.h@usask.ca; \\ Tel.: +1-306-966-6341; Fax: +1-306-966-6377.
}

Received: 27 March 2013; in revised form: 17 April 2013 / Accepted: 26 April 2013 /

Published: 14 May 2013

\begin{abstract}
Background: Low levels of circulating vitamin D are more likely to be found in those with darker skin pigmentation, who live in areas of high latitude, and who wear more clothing. We examined the prevalence of vitamin D deficiency and inadequacy in newcomer immigrant and refugee children. Methods: We evaluated circulating vitamin D status of immigrant children at the national level. Subsequently, we investigated vitamin D intake, circulating vitamin D status, and total body bone mineral content (TBBMC) in newcomer children living in Saskatchewan. Results: In the sample of newcomer children in Saskatchewan, the prevalence of inadequacy in calcium and vitamin D intakes was $76 \%$ and $89.4 \%$, respectively. Vitamin D intake from food/supplement was significantly higher in immigrants compared to refugees, which accords with the significant difference in serum status. Circulating vitamin D status indicated that $29 \%$ of participants were deficient and another $44 \%$ had inadequate levels of serum $25(\mathrm{OH}) \mathrm{D}$ for bone health. Dietary vitamin D intake, sex, region of origin, and length of stay in Canada were significant predictors of serum vitamin D status. Results for TBBMC revealed that $38.6 \%$ were found to have low TBBMC compared to estimated values for age, sex, and ethnicity. In the regression model, after controlling for possible confounders, children who were taller and had greater circulating vitamin D also had greater TBBMC. Nationally, immigrant children, particularly
\end{abstract}


girls, have significantly lower plasma 25(OH)D than non-immigrant children. Interpretation: Newcomer immigrant and refugee children are at a high risk of vitamin D deficiency and inadequacy, which may have serious negative consequences for their health.

Keywords: vitamin D; newcomer immigrant children; bone mineral status

\section{Introduction}

Recent studies report various health benefits for vitamin D along with its important role in bone health [1]. Limited food sources of vitamin D and long winters resulting in reduced sun exposure in Canada have raised concerns, particularly in growing children where vitamin D is needed for bone mineral accrual. National data report a low prevalence of vitamin D deficiency in children aged 6-11 years compared to other age groups [2]. However, the growing proportion of immigrants in Canada, particularly children, may represent communities at greater risk for vitamin D deficiency. Some new arrivals have high skin pigmentation, and social and cultural factors that can result in insufficient vitamin D intake from food [3-6]. From 2002 to 2004, 150 cases of rickets were reported in Canadian children [7]. Darker-skinned individuals represented $89 \%$ of cases, while $24 \%$ were immigrants [7]. In a cross-sectional study in Edmonton, vitamin D concentrations decreased in children as age increased [8]. The authors speculated that this is possibly due to less consumption of milk fortified with vitamin D and less exposure to the sun [8]. In response to the paucity of information in this area, we evaluated circulating vitamin D status of immigrant and refugee children new to Canada. Additionally, we examined the association between circulating vitamin $\mathrm{D}$ with bone mineral status.

\section{Methods}

Two studies were conducted to address the following research objectives: (i) to obtain a national perspective on vitamin D status of immigrant children in comparison to non-immigrant children; (ii) to evaluate determinants of vitamin $\mathrm{D}$ and its association with bone mineral status in children new to Canada.

\subsection{Study 1. Vitamin D Status of Canadian Immigrant and Non-Immigrant Children}

We used data from the Canadian Health Measures Survey (CHMS), cycle 1, 2007-2009, conducted by Statistics Canada [9]. The CHMS is a nationally representative survey among approximately 5500 Canadians aged 6-79 years, representative of 96.3\% of Canadians. Circulating 25-hydroxyvitamin D $[25(\mathrm{OH}) \mathrm{D}]$ levels were obtained for Canadian non-immigrant and first-generation immigrant children aged 6-11 years. In CHMS data, immigrants are not differentiated from refugees. The information on vitamin D measurement in the CHMS is found elsewhere [2]. Descriptive data are presented as mean \pm SEM. A statistically significant difference in vitamin D status among immigrant versus non-immigrant children is indicated by no overlap in 95\% Confidence Intervals [10]. As per Statistics Canada's recommendation, analyses were weighted and bootstrapped to obtain estimates 
representative of the Canadian population. Degree of freedom was considered 11 due to sampling structure, and alpha was set at 0.05. Data manipulation, cleaning, and creating new variables were done using SPSS 19. All analyses were conducted by STATA SE 11.

\subsection{Study 2. Healthy Immigrant Children (HIC)}

\subsubsection{Study Design and Participants}

In the absence of official data sources that identifies immigration status in Saskatchewan, a convenience sample of study participants $(n=72)$ were recruited with the assistance of several organizations that have regular contact with immigrant and refugees. These organizations include Saskatoon Open Door Society, Saskatchewan Intercultural Association, and ethno-cultural associations. Participant recruitment posters were also placed in accessible public locations including the universities, public libraries, health care facilities and commercial locations. Interpreters were used for $50(69 \%)$ participants while $22(31 \%)$ were able to speak English and, therefore, did not require an interpreter.

In a cross-sectional design (2010-2011), health and nutrition measures were collected from immigrant $(n=33)$ and refugee $(n=39)$ children aged $7-11$ years who had been living in Saskatoon, Saskatchewan, Canada for no more than five years. An immigrant is someone who "comes as a permanent resident to a country other than one's native land" [11]. A refugee is someone who "owing to well-founded fear of being persecuted for reasons of race, religion, nationality, membership of a particular social group or political opinion", is unable or unwilling to return to his/her country of birth due to fear for their safety [12]. This age range is an important time for bone acquisition and for establishing healthy dietary habits. Ethics approval was obtained from the University of Saskatchewan Biomedical Research Ethics Board (Bio \# 09-197).

\subsubsection{Data Collection}

Data collection for the study included multiple variables. Demographics and socioeconomic status were evaluated using questionnaires from the Canadian Community Health Survey [13]. Food security status was evaluated using the version of the United States Department of Agriculture questionnaire that was modified by Canada [14].

Anthropometric measurements included height, weight and waist circumference. Values were recorded in centimeters to the nearest millimeter. All measurements were taken twice for consistency to help eliminate human error. Percentile Body Mass Index (BMI) was categorized as normal, overweight, or obese according to World Health Organization (WHO) child classifications [15].

To assess physical activity, we used the CHMS children's physical activity questionnaire (CPA). Another variable was derived to examine sedentary activity in hours per day. Based on the CHMS, two questions on sun exposure were also included [9].

Three 24-h dietary recalls were administered to each child to obtain a usual intake. All 24-h recalls were administered at least three weeks apart and conducted in person. The child's caregiver assisted in the dietary assessments. Diet analyses were performed in "The Food Processor Nutrition and Fitness Software version SQL 10.5”, Esha Research, Salem, USA. Foods were categorized into food groups 
consistent with Eating Well with Canada's Food Guide [16]. To examine the overall nutrition status, we used the Canadian version of the Healthy Eating Index (HEIC) [17]. The HEIC has been validated and incorporates recommendations from Eating Well with Canada's Food Guide [17]. This index categorizes diets into one of three categories, "poor", "needs improvement", and "good" [17].

\subsubsection{Outcome Measures}

Blood samples were taken from 1 May to 30 September 2010 using a finger prick on eight 6-mm spots on a filter card. Circulating $25(\mathrm{OH}) \mathrm{D}$ was analyzed from dried blood spots, using a standard LC-MS/MS assay by ZRT Laboratory which is widely used for measuring 25-Hydroxy Vitamin D2/D3 [18,19]. The ZRT Laboratory participates in DEQAS, the Vitamin D Quality Assessment Scheme, which provides control samples to ensure assay accuracy [18,19]. Plasma and blood spot determinations were deemed to be equivalent because of the high stability of $25(\mathrm{OH}) \mathrm{D}$ in serum or plasma [20]. The blood spot card measurements of vitamin D levels are in agreement with serum and whole blood specimen [21]. Recent recommendations by the Institute of Medicine's dietary reference intake (DRI) panel on vitamin D were used to define vitamin D status including less than $30 \mathrm{nmol} / \mathrm{L}$ as deficient, $30-50 \mathrm{nmol} / \mathrm{L}$ as inadequate, and more than $50 \mathrm{nmol} / \mathrm{L}$ as sufficient [22].

Bone mineral status was assessed using Dual-energy X-ray Absorptiometry (DXA), Hologic Inc., Discovery-Wi, Bedford, USA, Serial \#80964. This study focused on Total Body Bone Mineral Content (TBBMC) as the most accurate measure in children [23]. The coefficient of variation for TBBMC in our laboratory is $0.5 \%$. Values obtained for TBBMC were compared to estimated normal values for each child's age, sex, and ethnicity based on data from four longitudinal studies [24].

\subsubsection{Statistical Analyses}

Descriptive statistics were analyzed by calculating means and standard deviations of variables of interest as well as the distribution of participants in various categories. We used a two-sided independent Student's $t$-test or non-parametric equivalent (Mann Whitney $U$-test) to investigate differences between refugees and immigrants and between males and females. Pearson's Chi square was used to analyze categorical variables. Finally, multivariate analyses (linear and logistic regression) were conducted to examine the association between variables of interest and health outcomes (vitamin D status, TBBMC), controlling for possible confounders. Analyses were conducted using PASW Statistics 18 by Polar Engineering and Consulting, Chicago, USA. In all analyses, alpha was set at 0.05. All data, when possible, was compared to Canadian published data.

\section{Results}

Descriptive data from CHMS revealed that mean plasma $25(\mathrm{OH}) \mathrm{D}$ concentrations in non-immigrant children was significantly higher than in immigrant children. This difference is over $20 \mathrm{nmol} / \mathrm{L}$ in immigrant girls (Table 1). 
Table 1. Plasma 25-hydroxyvitamin D $[25(\mathrm{OH}) \mathrm{D}](\mathrm{nmol} / \mathrm{L})$ concentrations in immigrant and non-immigrant children aged 6-11 years in Canada ${ }^{1}$.

\begin{tabular}{cc}
\hline Children aged 6-11 years & $\begin{array}{c}\text { Plasma 25-hydroxyvitamin D [25(OH)D] } \\
\text { (Mean } \pm \text { SEM) }\end{array}$ \\
\hline All children $(n=1,817,260)$ & $75.1 \pm 2.4$ \\
Boys & $79.9 \pm 2.0$ \\
Girls & $73.1 \pm 3.0$ \\
Immigrant children $(n=134,833)$ & $61.1 \pm 5.9 *$ \\
Immigrant boys & $69.0 \pm 7.9$ \\
Immigrant girls & $54.1 \pm 4.5 * *$ \\
Non-immigrant boys & $76.2 \pm 2.2$ \\
Non-immigrant girls & $77.5 \pm 1.9$ \\
Non-immigrant children $(n=1,682,427)$ & $74.7 \pm 2.8$ \\
\hline Data from the Canadian Health Measures Survey Cycle 1, 2007-2009. * Significantly lower than \\
non-immigrant children. ** Significantly lower than non-immigrant boys and girls.
\end{tabular}

In the HIC study, the mean \pm SD age of participants was $8.9 \pm 1.4$ years, with no significant difference between immigrants $(n=33)$ and refugees $(n=39)$. There was also no significant difference in distribution of males $(n=48)$ and females $(n=24)$ according to immigration status. Most immigrant children in the study were from the Middle East (73\%), while refugee children were from various regions including South East Asia, Africa, the Middle East and Latin America in descending order. In 2009, approximately 78\% of newcomers in Saskatchewan were from Asia and the Pacific (59.9\%), Africa and the Middle East (15.4\%) and South and Central America (2.5\%) [25]. These regions contribute to around $80 \%$ of immigrants in Canada [26]. The mean length of stay in Canada was $2.6 \pm 1.5$ years. Over $55 \%$ of families were from the lowest income bracket according to Statistics Canada classification.

Table 2 presents general characteristics of participants. Percentile height (mean \pm SD) was lower than the 50th percentile with no significant difference between immigrants and refugees. The majority of children were found to have a normal BMI while $22.2 \%$ were overweight and $6.9 \%$ were obese. Results showed $87.5 \%$ of immigrant and refugee newcomer children were obtaining the recommended number of hours per day of physical activity ( $\geq 60 \mathrm{~min}$ ) according to the Canadian Society for Exercise Physiology [27]. However, many participants were spending too much time ( $>2 \mathrm{~h} /$ day) in sedentary activities such as time spent watching television or movies, playing video games, or using the computer.

Table 2. General characteristics of healthy immigrant children study participants.

\begin{tabular}{cccc}
\hline Characteristics & $\begin{array}{c}\text { Immigrants } \\
\boldsymbol{n}=\mathbf{3 3}(\mathbf{4 5 . 8 \% )})\end{array}$ & $\begin{array}{c}\text { Refugees } \\
\boldsymbol{n}=\mathbf{3 9}(\mathbf{5 4 . 2 \%})\end{array}$ & $\begin{array}{c}\text { All participants } \\
\boldsymbol{n}=\mathbf{7 2}(\mathbf{1 0 0} \%)\end{array}$ \\
\hline Age (Mean \pm SD) & $8.9 \pm 1.6$ & $8.9 \pm 1.3$ & $8.9 \pm 1.4$ \\
Sex & & & \\
Male & $22(66.7 \%)$ & $26(66.7 \%)$ & $48(66.7 \%)$ \\
Female & $11(33.3 \%)$ & $13(33.3 \%)$ & $24(33.3 \%)$ \\
Length of stay in Canada in years (Mean \pm SD) & $2.6 \pm 1.5$ & $2.5 \pm 1.1$ & $2.5 \pm 1.3$ \\
\hline
\end{tabular}


Table 2. Cont.

\begin{tabular}{cccc}
\hline Height in cm $($ Mean \pm SD) & $132.6 \pm 13.2$ & $130.3 \pm 10.9$ & $131.4 \pm 12.0$ \\
Percentile Height $($ Mean \pm SD) & $49.7 \pm 31.1$ & $42.6 \pm 30.8$ & $45.8 \pm 31.0$ \\
Weight in kg (Mean \pm SD) & $32.1 \pm 10.6$ & $29.9 \pm 7.8$ & $30.9 \pm 9.2$ \\
Percentile Weight (Mean \pm SD) & $68.8 \pm 27.4$ & $64.9 \pm 28.8$ & $66.7 \pm 28.0$ \\
Physical activity in h/week (Mean \pm SD) & $13.1 \pm 5.4$ & $12.0 \pm 3.7$ & $12.5 \pm 4.6$ \\
Recommended level $(\geq 60$ min/day) & $29(87.9 \%)$ & $34(87.2 \%)$ & $63(87.5 \%)$ \\
Less than recommended level $(<60$ min/day) & $4(12.1 \%)$ & $5(12.8 \%)$ & $9(12.5 \%)$ \\
\hline
\end{tabular}

Dietary vitamin D and calcium intakes and HEIC are presented in Table 3. Only $24.2 \%$ of participants met recommendations for servings per day of milk and alternatives. The prevalence of calcium intake inadequacy was 76\%. Vitamin D intake from food and supplement was $213 \pm 195$ IU (mean $\pm \mathrm{SD}$ ) for all participants with a prevalence of inadequacy of $89.4 \%$. Only two children reported taking a vitamin D supplement regularly. Vitamin D intake from food and supplement was significantly higher in immigrants compared to refugees, which accords with the significant difference in serum status (Table 3). There was a significant difference in mean \pm SD HEIC scores between immigrants and refugees at $65.4 \pm 7.7 v s .60 .4 \pm 8.8$, respectively $(p=0.021)$. The majority of participants $(90.9 \%)$ needed to improve their diet. Only one immigrant was classified in "good" quality diet category based on HEIC, while no refugees did. There were also five refugees who had poor diets, while no immigrants did.

Table 3. Nutrient intake related to bone health.

\begin{tabular}{cccc}
\hline Characteristics & $\begin{array}{c}\text { Immigrants } \\
\boldsymbol{n}=\mathbf{3 3}(\mathbf{4 5 . 8 \%})\end{array}$ & $\begin{array}{c}\text { Refugees } \\
\boldsymbol{n}=\mathbf{3 9}(\mathbf{5 4 . 2 \%})\end{array}$ & $\begin{array}{c}\text { All participants } \\
\boldsymbol{n}=\mathbf{7 2}(\mathbf{1 0 0} \%)\end{array}$ \\
\hline Vitamin D intake in IU/day (Mean \pm SD) & $249 \pm 247$ & $181 \pm 130$ & $213 \pm 195$ \\
Prevalence of vitamin D intake inadequacy $[n(\%)]$ & $25(81 \%) *$ & $34(97 \%)$ & $59(89 \%)$ \\
Calcium intake in mg & $764 \pm 393$ & $676 \pm 380$ & $718 \pm 386$ \\
Prevalence of calcium intake inadequacy $[n(\%)]$ & $23(74 \%)$ & $27(77 \%)$ & $50(76 \%)$ \\
$\quad$ Milk and alternatives & & & \\
Mean intake (servings/day) & $1.9 \pm 1.2$ & $1.6 \pm 1.1$ & $1.7 \pm 1.2$ \\
Meeting Canada's Food Guide recommendations & $10(32.3 \%)$ & $6(17.1 \%)$ & $16(24.2 \%)$ \\
Healthy Eating Index Canada & & & \\
Mean Score & $65.4 \pm 7.7 *$ & $60.4 \pm 8.8$ & $62.7 \pm 8.6$ \\
Good Diet & $1(3.2 \%)$ & $0(0.0 \%)$ & $1(1.5 \%)$ \\
Diet Needs Improvement & $30(96.8 \%)$ & $30(85.7 \%)$ & $60(90.9 \%)$ \\
Poor Diet & $0(0.0 \%)$ & $5(14.3 \%)$ & $5(7.6 \%)$ \\
\hline
\end{tabular}

* Significantly different from refugee children, $t$-test $(P<0.05)$.

Total serum $25(\mathrm{OH}) \mathrm{D}(\mathrm{nmol} / \mathrm{L})$ was significantly higher in immigrant compared to refugee children ( $p=0.021$ ) (Table 4). Overall, 29\% of participants were vitamin D deficient and another $44 \%$ had inadequate levels of serum 25(OH)D for bone health [22]. Children spent $3.6 \pm 1.6 \mathrm{~h} /$ day (mean $\pm \mathrm{SD}$ ) in the sun in the summer months during peak times (11:00 am-4:00 pm), which was consistent across immigration status. Very few children regularly applied sunscreen, whereas more than half of children never did (Table 4). In linear regression analyses, after controlling for possible 
confounders including total caloric intake, age, sunscreen use, total hours spent in the sun in the summer months during peak times, and calcium intake; dietary vitamin D intake (Standardized Regression Coefficient: $0.46 \pm 0.11, p<0.001$ ), sex (Standardized Regression coefficient: $-0.39 \pm 0.11$, $p<0.001$ ), region of origin (Standardized Regression coefficient: $0.24 \pm 0.11, p=0.027$ ), and length of stay in Canada (Standardized Regression Coefficient: $-0.23 \pm 0.11, p=0.04$ ) were found to be significant predictors of serum vitamin D status. Females - those who had been living in Canada longer, those from regions with darker skin pigmentation, and those with lower vitamin D intake-were at greater risk of low circulating vitamin D.

Table 4. Vitamin D status of newcomer children.

\begin{tabular}{|c|c|c|c|}
\hline Characteristics & $\begin{array}{c}\text { Immigrants } \\
n=33(45.8 \%)\end{array}$ & $\begin{array}{c}\text { Refugees } \\
n=39(54.2 \%)\end{array}$ & $\begin{array}{l}\text { All participants } \\
n=72(100 \%)\end{array}$ \\
\hline $\mathrm{H} /$ day spent in the sun during peak times (Mean $\pm \mathrm{SD}$ ) & $3.6 \pm 1.7$ & $3.5 \pm 1.5$ & $3.6 \pm 1.6$ \\
\hline \multicolumn{4}{|l|}{ Sunscreen use } \\
\hline always & $0(0.00 \%)$ & $2(5.1 \%)$ & $2(2.8 \%)$ \\
\hline often & $4(12.1 \%)$ & $0(0.00 \%)$ & $4(5.6 \%)$ \\
\hline sometimes & $5(15.2 \%)$ & $10(25.6 \%)$ & $15(20.8 \%)$ \\
\hline rarely & $3(9.1 \%)$ & $5(12.8 \%)$ & $8(11.1 \%)$ \\
\hline never & $21(63.6 \%)$ & $22(56.4 \%)$ & $43(59.7 \%)$ \\
\hline Total serum vitamin $\mathrm{D}$ in $\mathrm{nmol} / \mathrm{L}(\mathrm{Mean} \pm \mathrm{SD})$ & $45.7 \pm 13.9 *$ & $37.8 \pm 15.5$ & $41.2 \pm 15.2$ \\
\hline Deficient and inadequate $<50 \mathrm{nmol} / \mathrm{L}$ & $19(63.3 \%)$ & $31(79.5 \%)$ & $50(72.5 \%)$ \\
\hline Sufficient $\geq 50 \mathrm{nmol} / \mathrm{L}$ & $11(36.7 \%)$ & $8(20.5 \%)$ & $19(27.5 \%)$ \\
\hline $\begin{array}{l}\text { Total body bone mineral content (TBBMC) } \\
\text { in grams }(\text { Mean } \pm \mathrm{SD})\end{array}$ & $984.9 \pm 245.0$ & $947.8 \pm 208.8$ & $964.6 \pm 224.9$ \\
\hline Low TBBMC & $13(41.9 \%)$ & $14(35.9 \%)$ & $27(38.6 \%)$ \\
\hline
\end{tabular}

* Significant difference from refugees; for means a $t$-test was used and for categorical variables chi square was used.

TBBMC was low in $38.6 \%$ of participants compared to estimated values for age, sex, and ethnicity [24]. In the regression model, after controlling for possible confounders, including immigration status; food security; age; sex; region of origin; physical activity level; total caloric intake; and intakes of calcium, magnesium, phosphorus, sodium, and caffeine, height and serum vitamin D status were found to be determinants of TBBMC (Table 5). Children who were taller and had greater serum vitamin D also had greater TBBMC.

Table 5. Factors associated with total body bone mineral content (TBBMC) in regression analysis (using the stepwise procedure) among all subjects $(n=56)$.

\begin{tabular}{ccccc}
\hline \multirow{2}{*}{$\begin{array}{c}\text { Outcome } \\
\text { variable }\end{array}$} & Constant & \multicolumn{2}{c}{ Regression coefficient } & Total $\boldsymbol{R}^{\mathbf{2}}$ \\
\cline { 3 - 5 } TBBMC & -1257.33 & $0.95 \pm 0.06$ & Serum vitamin D (nmol/L) & 0.82 \\
Partial $R^{2}$ & & 0.90 & $0.13 \pm 0.06$ & 0.27 \\
$p$-value & & $<0.001$ & 0.047 & \\
\hline
\end{tabular}


Table 5. Cont.

\begin{tabular}{ccccccc}
\hline \multirow{2}{*}{$\begin{array}{c}\text { Outcome } \\
\text { variable }\end{array}$} & Sex & $\begin{array}{c}\text { Region of } \\
\text { origin }\end{array}$ & Age & Calcium (mg) & $\begin{array}{c}\text { Calories } \\
\text { (kcal) }\end{array}$ & $\begin{array}{c}\text { Immigration } \\
\text { Status }\end{array}$ \\
\cline { 2 - 7 } & 0.01 & -0.09 & -0.12 & 0.07 & 0.07 & 0.05 \\
TBBMC & 0.03 & -0.20 & -0.17 & 0.13 & 0.14 & 0.12 \\
Partial $R^{2}$ & 0.832 & 0.147 & 0.227 & 0.353 & 0.323 & 0.408 \\
$p$-value & \multicolumn{7}{c}{ Excluded variables } \\
\hline \multirow{2}{*}{ Outcome } & H/week in & Food & Magnesium & Phosphorous & Sodium & Caffeine \\
variable & physical activities & security & (mg) & (mg) & (mg) & (mg) \\
\hline TBBMC & 0.02 & 0.11 & 0.06 & 0.06 & -0.04 & -0.03 \\
Partial $R^{2}$ & 0.03 & 0.23 & 0.11 & 0.11 & -0.08 & -0.06 \\
$p$-value & 0.805 & 0.095 & 0.419 & 0.434 & 0.574 & 0.660 \\
\hline
\end{tabular}

\section{Interpretation}

The HIC study is the first to evaluate vitamin D status of newcomer immigrant and refugee children aged 7-11 years in Canada. Data from a nationally representative sample showed alarmingly low $25(\mathrm{OH}) \mathrm{D}$ levels in immigrant children, particularly girls. HIC also showed a rate of $25(\mathrm{OH}) \mathrm{D}$ deficiency among newcomer immigrant and refugee children. Among these growing children, after controlling for biological and environmental co-factors, serum vitamin D was a significant predictor of TBBMC.

Using CHMS data, we previously reported Canadian children 6-11 years had higher 25(OH)D concentrations than adolescents and adults [2]. However, non-White Canadians were less likely to achieve recommended levels. This same study showed first generation immigrant children aged 6-11 years, particularly girls, had significantly lower $25(\mathrm{OH}) \mathrm{D}$ compared to their non-immigrant counterparts. Many newcomers have darker skin pigmentation and are, therefore, at greater risk for deficiency as melanin in the skin prevents the body from synthesizing vitamin D [28]. It is likely that females were at greater risk of deficiency than males due to cultural practices associated with greater covering of females causing insufficient skin exposure to the sun even though they may have been outdoors [28].

In the absence of comprehensive data on dietary intakes and other health measures in CHMS, specifically in newcomer children, data from HIC provides more insight into health concerns faced by this population. Many newcomer children, particularly refugees, did not have a good quality diet including dietary sources of vitamin D. However, vitamin D intake was still the main predictor of serum vitamin D. Circulating vitamin D of $75 \mathrm{nmol} / \mathrm{L}$ is considered beneficial for multiple health outcome [29]. None of the HIC participants met the $25(\mathrm{OH}) \mathrm{D}$ level of $75 \mathrm{nmol} / \mathrm{L}$ and over $29 \%$ were vitamin D deficient. This occurred even though non-Caucasian immigrant and refugee children spent almost four hours a day outside during peak times in summer months and the majority of participants rarely or never used sunscreen. It is more difficult to get the necessary vitamin D in areas of high latitude, especially during winter months [3-6]. This may explain why those who had been in Canada longer were at greater risk of deficiency; vitamin D stores are depleted each winter and not replenished enough in the summer. Girls, children with low vitamin D intake, those from regions with darker skin, 
and those with longer duration of stay in Canada were at higher risk of having inadequate/deficient levels of serum vitamin D.

Since bone mineral mass decreases with age, research has emphasized the importance of achieving optimal bone mineral accrual during childhood and adolescence, which will decrease skeletal-related health issues later in life [30-33]. Therefore, meeting requirements for vitamin D and calcium in these critical ages is crucial [34,35]. Most newcomer children in this study were not getting the recommended amounts of vitamin D and dietary calcium for bone health. Low intakes of calcium and vitamin D accord with low intakes of milk and alternatives, the main dietary sources of these two important nutrients [35]. Inadequate levels impede proper bone growth, which can result in stunting and increase the risk of developing osteoporosis in the future [4,5,22]. Serum vitamin D was a significant predictor of TBBMC in this study. TBBMC was lower than predicted values for age, sex and ethnicity in over $38 \%$ of participants. A recent Canadian study found significantly higher TBBMC values in Caucasian compared to Asian children [36]. There was no significant difference in TBBMC according to immigration status in HIC. Further research with a larger sample size is needed to examine TBBMC in children according to ethnicity.

The relatively small sample size in the HIC study may limit the conclusions. However, the accordance of HIC findings on serum vitamin D status of immigrant children with those from the CHMS confirms the importance of HIC results. In the absence of a large-scale comprehensive study on the nutrition and health status of newcomer children, our data could provide valuable insight into this area. HIC also distinguishes refugees from immigrants. Self-reported data on dietary intake using a 24-h recall is subject to under-reporting/over-reporting and omission of frequently forgotten items. To maximize accuracy of the data, we used three 24-h recalls where our expert research personnel used proper probing and assessment aids such as food model booklets, measuring cups and spoons, and color pictures for various food items to help recall names of food items. The premise of the study is to investigate and document disparities in and between host and mobile populations that reflect biological, social and behavioral differences between these populations. Defining these differences can lead to greater awareness of their existence in health providers who may appreciate them and assist those developing programs and policies to identify and mitigate preventable outcomes. Once a framework of existing disparities is defined, further investigation to explore and delineate specific co-founding factors can be undertaken.

\section{Conclusion}

In addition to the beneficial effects of vitamin $\mathrm{D}$ on bone, recent data on the association between vitamin D and chronic diseases including certain types of cancers, diabetes, and multiple sclerosis, demonstrate the importance of this nutrient in growing children [34,35]. Although more research is warranted, a considerably high rate of vitamin D intake inadequacy and serum deficiency/inadequacy in newcomer children is already associated with bone mineral mass during pre-adolescence. This, therefore, requires preventive interventions to minimize the risk of serious vitamin D related diseases. 


\section{References}

1. Wacker, M.; Holick, M.F. Vitamin D-effects on skeletal and extraskeletal health and the need for supplementation. Nutrients 2013, 5, 111-148.

2. Whiting, S.J.; Langlois, K.A.; Vatanparast, H.; Greene-Finestone, L.S. The vitamin D status of Canadians relative to the 2011 Dietary Reference Intakes: An examination in children and adults with and without supplement use. Am. J. Clin. Nutr. 2011, 94, 128-135.

3. Grant, W.B.; Holick, M.F. Benefits and requirements of vitamin D for optimal health: A review. Altern. Med. Rev. 2005, 10, 94-111.

4. Hintzpeter, B.; Scheidt-Nave, C.; Muller, M.J.; Schenk, L.; Mensink, G.B. Higher prevalence of vitamin $\mathrm{D}$ deficiency is associated with immigrant background among children and adolescents in Germany. J. Nutr. 2008, 138, 1482-1490.

5. Mithal, A.; Wahl, D.A.; Bonjour, J.P.; Burckhardt, P.; Dawson-Hughes, B.; Eisman, J.A.; El-Haji Fuleihan, G.; Josse, R.G.; Lips, P.; Morales-Torres, J. Global vitamin D status and determinants of hypovitaminosis D. Osteoporos. Int. 2009, 20, 1807-1820.

6. Van der Meer, I.M.; Karamali, N.S.; Boeke, A.J.; Lips, P.; Middelkoop, B.J.; Verhoeven, I.; Wuister, J.D. High prevalence of vitamin D deficiency in pregnant non-Western women in The Hague, Netherlands. Am. J. Clin. Nutr. 2006, 84, 350-353.

7. Ward, L.M.; Gaboury, I.; Ladhani, M.; Zlotkin, S. Vitamin D-decifiency rickets among children in Canada. CMAJ 2007, 177, 161-166.

8. Roth, D.E. Bones and beyond: An update on the role of vitamin D in child and adolescent health in Canada. Appl. Physiol. Nutr. Metab. 2007, 32, 770-777.

9. Statistics Canada. Canadian Health Measures Survey (Detailed information for Spring 2007 to Spring 2009 (Cycle 1)), 2010. Available online: http://www.statcan.gc.ca/cgi-bin/imdb/ p2SV.pl? Function $=$ getSurvey $\&$ SDDS $=5071 \&$ lang $=\mathrm{en} \& \mathrm{db}=\mathrm{imdb} \& \mathrm{adm}=8 \& \mathrm{dis}=2 \quad$ (accessed on 30 August 2012).

10. Health Canada. Canadian Community Health Survey Cycle 2.2, Nutrition (2004)—A Guide to Accessing and Interpreting the Data. Available online: http:/www.hc-sc.gc.ca/fn-an/alt_formats/ hpfb-dgpsa/pdf/surveill/cchs-guide-escc-eng.pdf (accessed on 25 August 2012).

11. Immigration. In Canadian Oxford Dictionary; Oxford University Press: New York, NY, USA, 2011. Available online: http://www.oxfordreference.com/views/SEARCH_RESULTS.html?y=14\&q= immigrate $\&$ category $=\mathrm{t} 150 \& \mathrm{x}=4 \& \mathrm{ssid}=865872107 \&$ scope $=$ book $\&$ time $=0.830259983485593$ (accessed on 15 August 2012).

12. United Nations High Commissioner for Refugees. Convention Relating to the Status of Refugees Article, 1951. Available online: http://www2.ohchr.org/English/law/refugees.htm\#wp1037003 (accessed on 15 August 2012).

13. Statistics Canada. Master and share files derived variables documentation, 2008. Available online: http://www.statcan.gc.ca/imdb-bmdi/document/5049_D11_T9_V1-eng.pdf (accessed on 27 August 2012). 
14. Health Canada. Canadian Community Health Survey, Cycle 2.2, Nutrition (2004) - Income-related household food security in Canada. Ottawa (ON): Office of Nutrition Policy and Promotion Health Products and Food Branch, 2007. Available online: http://www.hc-sc.gc.ca/fn-an/ alt_formats/hpfb-dgpsa/pdf/surveill/income_food_sec-sec_alim-eng.pdf (accessed on 19 July 2012).

15. World Health Organization. Growth reference 5-19 years, 2007. Available online: http://www. who.int/growthref/en/ (accessed on 19 July 2012).

16. Health Canada. Eating well with Canada's food guide, 2007. Available online: http://www. hc-sc.gc.ca/fn-an/food-guide-aliment/index-eng.php (accessed on 11 June 2012).

17. Garriguet, D. Diet quality in Canada. Health Rep. 2009, 20, 41-52.

18. Eyles, D.; Anderson, C.; Ko, P.; Jones, A.; Thomas, A.; Burne, T.; Mortensen, P.B.; Norgaard-Pedersen, B.; Hougaard, D.M.; McGrath, J. A sensitive LC/MS/MS assay of $25 \mathrm{OH}$ vitamin D3 and 25OH vitamin D2 in dried blood spots. Clin. Chim. Acta 2009, 403, 145-151.

19. Newman, M.S.; Brandon, T.R.; Groves, M.N.; Gregory, W.L.; Kapur, S.; Zava, D.T. A liquid chromatography/tandem mass spectrometry method for determination of 25-hydroxi vitamin D2 and 25-hydroxy vitamin D3 in dried blood spots: A potential adjunct to diabetes and cardiometabolic risk screening. J. Diabetes Sci. Technol. 2009, 3, 156-162.

20. Hollis, B.W. Measuring 25-hydroxyvitamin D in a clinical environment: Challenges and needs. Am. J. Clin. Nutr. 2008, 88, 507S-510S.

21. Larkin, E.K.; Gebretsadik, T.; Koestner, N.; Newman, M.S.; Liu, Z.; Carroll, K.N.; Minton, P.; Woodward, K.; Hartert, T.V. Agreement of blood spot card measurements of vitamin D levels with serum, whole blood specimen types and a dietary recall instrument. PLoS One 2011, $6, \mathrm{e} 16602$.

22. Institute of Medicine. Dietary reference intakes for calcium and vitamin D; The National Academies Press: Washington, DC, USA, 2010. Available online: http://www.iom.edu/Reports/ 2010/Dietary-Reference-Intakes-for-Calcium-and-Vitamin-D.aspx (accessed on 27 August 2012).

23. Fewtrell, M.S. Bone densitometry in children assessed by dual X ray absorptiometry: Uses and pitfalls. Arch. Dis. Child. 2003, 88, 795-798.

24. Baxter-Jones, A.D.; Burrows, M.; Bachrach, L.K.; Lloyd, T.; Petit, M.; Macdonald, H.; Mirwald, R.L.; Bailey, D.; McKay, H. International longitudinal pediatric reference standards for bone mineral content. Bone 2009, 46, 208-216.

25. Government of Saskatchewan. Saskatchewan Statistical Immigration Report 2009, 2008. Available online http://aeel.gov.sk.ca/sk-immigration-statistical-report-2009 (accessed on 23 August 2012).

26. Citizenship and Immigration Canada facts and figures 2011. Available online: http://www. cic.gc.ca/english/pdf/research-stats/facts2011.pdf (accessed on 23 August 2012).

27. Canadian Society for Exercise Physiology, Communique, March Newsletter. Available online: http://www.csep.ca/english/view.asp? $x=804$ (accessed on 27 August 2012).

28. Nellen, J.F.; Smulders, Y.M.; Frissen, P.H.; Slaats, E.H.; Silberusch, J. Hypovitaminosis D in immigrant women: Slow to be diagnosed. BMJ 1996, 312, 570-572.

29. Wimalawansa, S.J. Vitamin D in the new millennium. Curr. Osteoporos. Rep. 2012, 10, 4-15.

30. Caradonna, P.; Rigante, D. Bone health as a primary target in the pediatric age. Eur. Rev. Med. Pharmacol. Sci. 2009, 13, 117-128. 
31. Nichols, D.L.; Sanborn, C.F.; Essery, E.V.; Clark, R.A.; Letendre, J.D. Impact of curriculum-based bone loading and nutrition education program on bone accrual in children. Pediatr. Exerc. Sci. 2008, 20, 411-425.

32. Vatanparast, H.; Baxter-Jones, A.; Faulkner, R.A.; Bailey, D.A.; Whiting, S.J. Positive effects of vegetable and fruit consumption and calcium intake on bone mineral accrual in boys during growth from childhood to adolescence: The University of Saskatchewan Pediatric Bone Mineral Accrual Study. Am. J. Clin. Nutr. 2005, 82, 700-706.

33. Bailey, D.A.; Faulkner, R.A.; McKay, H.A. Growth, physical activity, and bone mineral acquisition. Exerc. Sport Sci. Rev. 1996, 24, 233-266.

34. Whiting, S.J.; Calvo, M.S. Dietary recommendations for vitamin D: A critical need for functional end points to establish an estimated average requirement. J. Nutr. 2005, 135, 304-309.

35. Holick, M.F. Health benefits of vitamin D and sunlight: A D-bate. Nat. Rev. Endocrinol. 2011, 7 , 73-75.

36. Burrows, M.; Baxter-Jones, A.; Mirwald, R.; Macdonald, H.; McKay, H. Bone mineral accrual across growth in a mixed-ethnic group of children: Are Asian children disadvantaged from an early age? Calcif. Tissue Int. 2009, 84, 366-378.

(C) 2013 by the authors; licensee MDPI, Basel, Switzerland. This article is an open access article distributed under the terms and conditions of the Creative Commons Attribution license (http://creativecommons.org/licenses/by/3.0/). 